\title{
Fried frailty phenotype assessment components as applied to geriatric inpatients
}

\author{
This article was published in the following Dove Press journal: \\ Clinical Interventions in Aging \\ 22 April 2016 \\ Number of times this article has been viewed
}

\section{Joanna Bieniek \\ Krzysztof Wilczyński \\ Jan Szewieczek}

Department of Geriatrics, School of Health Sciences in Katowice, Medical University of Silesia, Katowice, Poland
Correspondence: Jan Szewieczek Department of Geriatrics, School of Health Sciences in Katowice, Medical University of Silesia, GCM, ul Ziolowa 45/47, Katowice 40-635, Poland

$\mathrm{Tel}+48323598239$

Fax +48 322059483

Email jszewieczek@sum.edu.pl
Background: Management of geriatric patients would be simplified if a universally accepted definition of frailty for clinical use was defined. Among definitions of frailty, Fried frailty phenotype criteria constitute a common reference frame for many geriatric studies. However, this reference frame has been tested primarily in elderly patients presenting with relatively good health status.

Objective: The aim of this article was to assess the usefulness and limitations of Fried frailty phenotype criteria in geriatric inpatients, characterized by comorbidity and functional impairments, and to estimate the frailty phenotype prevalence in this group.

Patients and methods: Five hundred consecutive patients of the university hospital subacute geriatric ward, aged 79.0 8.4 years (67\% women and 33\% men), participated in this crosssectional study. Comprehensive geriatric assessment and Fried frailty phenotype component evaluation were performed in all patients.

Results: Multimorbidity ( $6.0 \pm 2.8$ diseases) characterized our study group, with a wide range of clinical conditions and functional states (Barthel Index of Activities of Daily Living 72.2 \pm 28.2

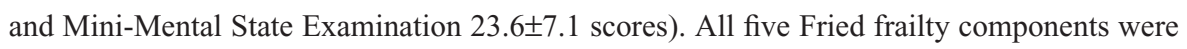
assessed in $65 \%$ of patients ( $95 \%$ confidence interval $[\mathrm{CI}]=60.8-69.2)$ (diagnostic group). One or more components were not feasible to be assessed in $35 \%$ of the remaining patients (nondiagnostic group) because of lack of past patient's body mass control and/or cognitive or physical impairment. Patients from the nondiagnostic group, as compared to patients from the diagnostic group, presented with more advanced age, higher prevalence of dementia, lower prevalence of hypertension, lower systolic and diastolic blood pressure, body mass index, Mini-Mental State Examination and Barthel Index of Activities of Daily Living. Despite diagnostic limitations, we found $\geq 3$ positive criteria (thus, frailty diagnosis) in $54.2 \%$ of the study group ( $95 \%$ $\mathrm{CI}=49.8-58.6$ ), with prevalence from $31.7 \%$ in sexagenarians to $67.6 \%$ in nonagenarians.

Conclusion: Fried frailty phenotype criteria seem useful for geriatric inpatient assessment, despite diagnostic limitations. High prevalence of frailty among geriatric inpatients suggests that evaluation for frailty should be considered a part of the comprehensive geriatric assessment.

Keywords: frail older adults, frailty phenotype, geriatric ward, multimorbidity, comprehensive geriatric assessment, geriatric subacute care

\section{Background}

Population aging is increasing the demand for health and social care services. Frailty affects a significant proportion of the elderly population and requires a unique approach to caregiving. ${ }^{1}$ The multidimensional nature of frailty as a medical syndrome of ageassociated decline in physiologic reserve and function across multiple organ systems, resulting in diminished strength and endurance, increased vulnerability to stressors, risk of falls, disability, hospitalization, and mortality, has been broadly accepted. ${ }^{2-5}$ 
However, there is no consensus regarding a single definition of frailty for clinical use. ${ }^{3,4}$ Frailty can be physical or psychological or a combination of both. , $^{2,6}$ Popular definitions of physical frailty include a specific phenotype model consisting of five items ${ }^{2,7}$ and a frailty index defined as the proportion of accumulated deficits. ${ }^{8-10}$ Although a number of other definitions have been developed, the frailty criteria worked out by Fried et $\mathrm{al}^{2}$ still constitute a reference frame for many studies in community-dwelling populations, ${ }^{5,7,11-13}$ as opposed to geriatric unit inpatient populations. ${ }^{2}$ A consensus exists that one of the primary purposes of diagnosing frailty is to identify nonrobust and nondisabled older patients at risk of adverse health outcomes in the near future. ${ }^{3}$ However, frailty can coexist with disability and comorbidity; ${ }^{2,14,15}$ thus, the diagnosis of frailty can be even more useful in managing older people with chronic diseases and disability. ${ }^{3}$ Fried et $\mathrm{al}^{2}$ excluded patients with a history of Parkinson's disease, stroke, and considerable cognitive impairment (Mini-Mental scores $<18$ ) and patients treated with antidepressants from their study. However, Parkinson's diseaseassociated motor decline can contribute to frailty, ${ }^{16}$ stroke has been identified as a risk factor for frailty, ${ }^{17}$ individuals with cognitive impairment are more prone to become frail, ${ }^{18}$ as well as a substantial correlation of frailty and depression in late life has been revealed. ${ }^{19}$ Participants enrolled in the study performed by Fried et $\mathrm{al}^{2}$ were younger, less likely to report limitations in activity, less likely to have high blood pressure and stroke, and more likely to perceive their health status as very good or excellent, when compared to those who were ineligible or who refused. ${ }^{20}$ Thus, it can be assumed that the Cardiovascular Health Study population presented better health status than geriatric patients with coexistent medical, functional, psychological, and social problems, who are referred to the hospital and need comprehensive geriatric assessment (CGA). ${ }^{21,22}$ Frailty measures other than frailty phenotype, such as modified frailty index ${ }^{23}$ and Clinical Frailty Scale, ${ }^{24}$ were applied in such patients in different hospital settings..$^{23,25,26}$ In a recently published study, accuracy of the Clinical Frailty Scale and the frailty phenotype as predictors of mortality and other clinical outcomes in a cohort of older geriatric ward patients was analyzed. ${ }^{27}$ However, operationalized components proposed by Rockwood et $\mathrm{al}^{10}$ for frailty phenotype assessment were applied in this study.

We examined the usefulness and diagnostic limitations of individual frailty assessment criteria proposed by Fried et $\mathrm{al}^{2}$ in the setting of a geriatric subacute ward. Additionally, the prevalence of frailty was assessed according to Fried criteria in this population.

\section{Methods}

\section{Participants}

The study comprised 500 consecutive patients aged $79.0 \pm 8.4$ years $(\bar{x} \pm$ standard deviation $[\mathrm{SD}])$, among them $67 \%$ women and $33 \%$ men were admitted to the subacute geriatric ward - Department of Geriatrics at the large multiprofile University Hospital No 7, Upper Silesian Medical Center in Katowice, Poland, between October 2013 and May 2014.

\section{Measurements}

CGA with tests for frailty and body mass assessment was performed for all patients. CGA included a structured interview, physical examination, geriatric functional assessment, blood sampling, ECG, abdominal ultrasound, and chest X-ray. The Mini-Mental State Examination (MMSE) ${ }^{28}$ was used to assess global cognitive performance and Geriatric Depression Scale (GDS)-Short Form to identify depression. ${ }^{29}$ The Barthel Index of Activities of Daily Living (Barthel Index) ${ }^{30}$ and Lawton's Instrumental Activities of Daily Living (IADL) Scale $^{31}$ were used to determine the functional status. The MMSE scores range from 0 to 30, the Barthel Index scores range from 0 to 100, and IADL scores range from 9 to 27; higher scores indicate better functional state. Geriatric Depression Scale-Short Form scores range from 0 to 15 with higher scores indicating higher depression probability. Modified get-up and go test, ${ }^{32}$ scored from 0 to 10 with lower values indicating higher balance disorders, was used to assess the risk of falls. Frailty was diagnosed according to the Fried ${ }^{2}$ criteria. A Polish language version of the protocol Frailty Assessment Components: Standardized Protocols was used. These criteria include five components:

1. Unintentional weight loss of $>10 \mathrm{lbs}$ ( $\geq 4.5 \mathrm{~kg}$ ) or $\geq 5 \%$ of body mass in the last year (obtained from patient, caregiver, or medical records);

2. Weakness (assessment based on the handgrip strength measurement; interpretation of results takes into account sex and body mass index [BMI]). A Kern digital dynamometer was used for grip strength measurement;

3. Exhaustion (audited information based on two questions from Center for Epidemiological Studies Depression (CES-D) scale; ${ }^{33}$ a score from 1 [fatigue or exhaustion felt rarely or not at all] to 4 [fatigue or exhaustion felt most of the time], 3 or 4 points means that the test is positive for decreased physical activity);

4. Slow gait (walking time over a distance of $15 \mathrm{ft}$ [4.57 m]; interpretation of results takes into account sex and height);

5. Low physical activity (energy expenditure weekly rate calculated on the basis of the modified questionnaire Minnesota Leisure Time Activity Questionnaire). ${ }^{34,35}$ 
Patients who fulfilled none of the criteria were considered nonfrail, patients who fulfilled 1 and 2 criteria were classified as prefrail, and patients who fulfilled $\geq 3$ criteria were classified as frail. ${ }^{2}$ We had expected that some components of frailty criteria, for example, gait speed assessment, would be impossible to perform or assess in the part of our study population. For this reason, we decided to distinguish patients for whom we could obtain all criteria (diagnostic group or D group) and patients for whom one or more criteria could not be obtained (nondiagnostic group or ND group). BMI was calculated for all patients.

\section{Statistical analysis}

The obtained data were analyzed using the STATISTICA software Version 10 (StatSoft, Inc., USA). In the analysis of differences between groups, we used $\chi^{2}$ test and the Mann-Whitney $U$ statistic. $P$-values $<0.05$ were considered statistically significant.

\section{Ethics}

The study protocol was registered with the Bioethical Committee of the Medical University of Silesia in Katowice. In a statement, the committee determined that "the study is characterized by record review and in the context of law is not a medical experiment and does not require assessment by the bioethical committee" (Letter KNW/0022/ $\mathrm{KB} / 207 / 13$ ). Based on this decision, written informed consent was not required of our study nor was separate patient consent required for our statistical analysis or research since patient data is not disclosed outside internal hospital ward staff.

\section{Results}

Our study group consisted of patients who represent a wide range of clinical conditions and functional states (Barthel Index $72.2 \pm 28.2$ scores in the range from 0 to

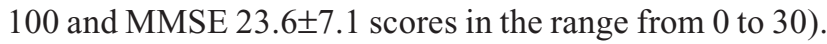
A common feature was multimorbidity (mean number of diseases $6.0 \pm 2.8$ in the range from 1 to 15 ), with hypertension, osteoarthritis, coronary artery disease, chronic heart failure, diabetes, and dementia as the primary conditions leading to morbidity (Table 1). All five frailty criteria as defined by Fried et $\mathrm{al}^{2}$ were possible to assess in $65 \%$ of our study group (325 patients: 213 women and 112 men; 95\% CI $=60.8-69.2$ ), while assessment of all criteria was not possible in $35 \%$ of patients (175 patients in the entire

Table I Comparison between ND group and D group according to clinical and functional measures

\begin{tabular}{|c|c|c|c|c|}
\hline Indicator & $\begin{array}{l}\text { Whole group } \\
(n=500)\end{array}$ & $\begin{array}{l}\text { ND group } \\
(n=\mid 75)\end{array}$ & $\begin{array}{l}\text { D group } \\
(n=325)\end{array}$ & $\begin{array}{l}P \text {-value } \\
\text { (group D vs ND) }\end{array}$ \\
\hline Age (years) & $79.0 \pm 8.4$ & $8 \mathrm{I} .4 \pm 7.4$ & $77.7 \pm 7.3$ & $<0.001$ \\
\hline Sex (\% of women) & 67 & 70 & 66 & 0.140 \\
\hline Number of diseases & $6.0 \pm 2.8$ & $6.0 \pm 2.9$ & $6.0 \pm 2.8$ & 0.640 \\
\hline Hypertension (\% of patients) & 84 & 77 & 87 & 0.001 \\
\hline Osteoarthritis (\% of patients) & 61 & 55 & 64 & 0.026 \\
\hline Coronary artery disease (\% of patients) & 59 & 54 & 62 & 0.058 \\
\hline Chronic heart failure (\% of patients) & 43 & 42 & 43 & 0.384 \\
\hline Diabetes mellitus (\% of patients) & 34 & 31 & 35 & 0.205 \\
\hline Cardiac arrhythmia (\% of patients) & 34 & 31 & 36 & 0.124 \\
\hline Dementia (\% of patients) & 24 & 44 & 14 & $<0.001$ \\
\hline Osteoporosis (\% of patients) & 23 & 20 & 25 & 0.107 \\
\hline Anemia (\% of patients) & 22 & 26 & 19 & 0.051 \\
\hline Prior stroke (\% of patients) & 18 & 19 & 17 & 0.294 \\
\hline Prior myocardial infarction (\% of patients) & 13 & 11 & 14 & 0.250 \\
\hline Cancer (\% of patients) & 12 & 14 & 11 & 0.148 \\
\hline Parkinson's disease (\% of patients) & 7 & 8 & 6 & 0.260 \\
\hline Heart rate (beats per minute) & $72.1 \pm I 1.2$ & $73.8 \pm 12.3$ & $71.2 \pm 10.6$ & 0.069 \\
\hline Systolic blood pressure $(\mathrm{mmHg})$ & $135.4 \pm 19.8$ & $133.0 \pm 19.1$ & $|36.8 \pm 20|$. & 0.030 \\
\hline Diastolic blood pressure $(\mathrm{mmHg})$ & $76.8 \pm 10.8$ & $75.5 \pm 10.2$ & $77.5 \pm 11.1$ & 0.050 \\
\hline Barthel Index (points) & $72.2 \pm 28.2$ & $50.4 \pm 30.4$ & $83.9 \pm 18.2$ & $<0.001$ \\
\hline IADL (points) & $18.8 \pm 6.5$ & $14.2 \pm 6.4$ & $21.4 \pm 5.1$ & $<0.001$ \\
\hline MMSE (points) & $23.6 \pm 7.1$ & $19.4 \pm 8.0$ & $26.2 \pm 4.3$ & $<0.001$ \\
\hline GDS (points) & $5.1 \pm 3.1$ & $5.5 \pm 2.9$ & $5.0 \pm 3.2$ & 0.026 \\
\hline BMI $\left(\mathrm{kg} / \mathrm{m}^{2}\right)$ & $27.8 \pm 5.9$ & $26.7 \pm 6.1$ & $28.2 \pm 5.8$ & 0.027 \\
\hline Modified get-up and go test (points) & $4.5 \pm 2.7$ & $2.6 \pm 2.3$ & $5.6 \pm 2.2$ & $<0.001$ \\
\hline
\end{tabular}

Note: Data is formatted as mean \pm standard deviation unless otherwise noted

Abbreviations: BMI, body mass index; D, diagnostic; GDS, Geriatric Depression Scale; IADL, Instrumental Activities of Daily Living; MMSE, Mini-Mental State Examination; ND, nondiagnostic. 
Table 2 Factors leading to diagnostic component failure in the application of Fried frailty criteria in geriatric inpatients $(n=500)$

\begin{tabular}{|c|c|c|c|c|}
\hline \multirow[t]{2}{*}{ Criteria } & \multirow[t]{2}{*}{ Test component failure factor } & \multicolumn{3}{|c|}{ Number of patients } \\
\hline & & $\mathbf{n}$ & $\%$ & $95 \% \mathrm{Cl}$ \\
\hline \multicolumn{5}{|c|}{ Criterion I. Unintentional weight loss over the last year } \\
\hline \multirow[t]{3}{*}{ Interview or medical records analysis } & I. Lack of weight control in the past & 50 & 10 & $7.4-12.6$ \\
\hline & 2. Cognitive disorders - inability to respond the question & 87 & 17.4 & 14.1-20.7 \\
\hline & Total $(I+2)$ & 137 & 27.4 & $23.5-31.3$ \\
\hline \multicolumn{5}{|l|}{ Criterion 2. Weakness } \\
\hline \multirow[t]{5}{*}{ The measurement of handgrip strength } & I. Cognitive disorders - inability to understand commands & 26 & 5.2 & $3.3-7.1$ \\
\hline & 2. Contraindication for the test & 4 & 0.8 & $0.0-1.6$ \\
\hline & 3. Lack of consent for the test & 2 & 0.4 & $0.0-1.0$ \\
\hline & 4. The test not completed & 6 & 1.2 & $0.2-2.2$ \\
\hline & Total $(I+2+3+4)$ & 38 & 7.6 & $5.3-9.9$ \\
\hline \multicolumn{5}{|l|}{ Criterion 3. Exhaustion } \\
\hline A standardized interview by questionnaire & I. Cognitive disorders - inability to respond & 54 & 10.8 & $8.1-13.5$ \\
\hline \multicolumn{5}{|l|}{ Criterion 4. Slow gait } \\
\hline \multirow[t]{4}{*}{ The measurement of the transit time of $4.57 \mathrm{~m}$} & I. Inability to walk & 70 & 14 & $11.0-17.0$ \\
\hline & 2. Cognitive disorders - inability to understand commands & 17 & 3.4 & $1.8-5.0$ \\
\hline & 3. The test not completed & 4 & 0.8 & $0.0-1.6$ \\
\hline & Total $(I+2+3)$ & 91 & 18.2 & $|4.8-2| .6$ \\
\hline \multicolumn{5}{|l|}{ Criterion 5. Low physical activity } \\
\hline A standardized interview by questionnaire & I. Cognitive disorders - inability to respond & 59 & 11.8 & $9.0-14.6$ \\
\hline
\end{tabular}

Abbreviation: $\mathrm{Cl}$, confidence interval.

group: 123 women and 52 men; 95\% CI =30.8-39.2). ND group, as compared to D group, presented similar comorbidity but represented increased age, higher prevalence of dementia, lower prevalence of hypertension and osteoarthritis, lower systolic blood pressure, BMI, MMSE, Barthel Index, and IADL scores, as well as lower modified get-up and go test scores (Table 1). Assessing weight loss from 1 year ago proved to be the most difficult criterion to assess (in 137 patients), because data on body weight from a year ago were seldom available. Specific reasons were inability to obtain any information because of cognitive disorders in 87 patients (17\% of the entire study group) or the lack of body weight measurement in the past (50 patients or $10 \%$ of all). Cognitive impairment was also an essential cause of diagnostic failure in other frailty criteria (Table 2). Ninety patients $(51.4 \%)$ in the ND group had three or four positive frailty criteria, while 181 patients $(55.7 \%)$ had three or more positive criteria $(P=0.361)$ in the $\mathrm{D}$ group (Table 3$)$. In the entire study group, 271 patients $(54.2 \%)$ had $\geq 3$ positive components and, thus, fulfilled the diagnosis of frailty as defined by Fried frailty criteria. Apart from the body weight component, all tests for frailty gave worse results in ND group patients - both in women and men (Table 4). Analysis of our study group revealed frailty in $31.7 \%$ of patients aged $60-69$ years and in $67.6 \%$ of patients aged 90 years or older, with an average of $54.2 \%$ rate of frailty for the entire study group (Table 5).

\section{Discussion}

There is increasing evidence of the prognostic significance of frailty in elderly patients for a variety of different medical conditions. These conditions include diabetes, ${ }^{36}$ heart failure, ${ }^{37}$ acute coronary syndrome, ${ }^{38}$ femoral fracture, ${ }^{23}$ cancer, ${ }^{39}$ Alzheimer's disease, ${ }^{40}$ major surgery, ${ }^{41}$ and hospitalization at the internal medicine ward. ${ }^{25}$ Thus, frailty assessment in elderly populations may be significant for patient management personalization, allowing reduction in both excessive complications and costs of undertreatment and overtreatment. ${ }^{40,42-44}$ However, the lack of consensus for a universal definition of frailty for clinical use limits the application of the diagnosis of frailty syndrome in clinical practice. An impediment for a universal definition of frailty is

Table 3 Comparison between ND group and D group according to Fried frailty criteria score

\begin{tabular}{|c|c|c|c|c|c|}
\hline \multirow{3}{*}{$\begin{array}{l}\text { Number } \\
\text { of positive } \\
\text { criteria }\end{array}$} & \multicolumn{4}{|c|}{ Number of patients } & \multirow[t]{3}{*}{$P$-value } \\
\hline & \multicolumn{2}{|c|}{$\begin{array}{l}\text { ND group } \\
(n=\mid 75)\end{array}$} & \multicolumn{2}{|c|}{$\begin{array}{l}\text { D group } \\
(n=325)\end{array}$} & \\
\hline & $n$ & $\%$ & $\mathbf{n}$ & $\%$ & \\
\hline 0 & 26 & 15 & 24 & 7 & 0.004 \\
\hline I & 32 & 18 & 53 & 16 & 0.287 \\
\hline 2 & 27 & 15 & 67 & 21 & 0.078 \\
\hline 3 & 46 & 26 & 70 & 22 & 0.115 \\
\hline 4 & 44 & 25 & 75 & 23 & 0.302 \\
\hline 5 & 0 & 0 & 36 & II & $<0.001$ \\
\hline
\end{tabular}

Note: $P$-values for differences according to $\chi^{2}$ test are presented. Abbreviations: $\mathrm{D}$, diagnostic; ND, nondiagnostic. 
Table 4 Fried frailty criteria assessment of the ND and D groups according to sex

\begin{tabular}{|c|c|c|c|c|c|c|c|c|c|c|}
\hline \multirow[t]{4}{*}{ Frailty component } & \multicolumn{10}{|c|}{ Measurement results } \\
\hline & \multicolumn{5}{|c|}{ Women } & \multicolumn{5}{|c|}{ Men } \\
\hline & \multicolumn{2}{|c|}{ Group ND } & \multicolumn{2}{|c|}{ Group D } & \multirow[t]{2}{*}{$P$-value } & \multicolumn{2}{|c|}{ Group ND } & \multicolumn{2}{|c|}{ Group D } & \multirow[t]{2}{*}{$P$-value } \\
\hline & $\mathbf{n}$ & $x \pm$ SD & $\mathbf{n}$ & $x \pm S D$ & & $\mathbf{n}$ & $x \pm$ SD & $\mathbf{n}$ & $x \pm$ SD & \\
\hline Change in body weight in the last year $(\mathrm{kg})$ & 27 & $-5.2 \pm 9.3$ & 213 & $-2.5 \pm 7.0$ & 0.119 & 12 & $-7.0 \pm 8.9$ & 112 & $-2.2 \pm 4.7$ & 0.064 \\
\hline Handgrip strength (kg) & 101 & $10.4 \pm 4.3$ & 213 & $13.6 \pm 5.8$ & $<0.001$ & 36 & $18.0 \pm 6.9$ & 112 & $28.6 \pm 10.0$ & $<0.001$ \\
\hline Physical capacity (CES-D scale) (points) & 92 & $3.2 \pm 0.8$ & 213 & $2.9 \pm 0.9$ & 0.043 & 31 & $3.1 \pm 0.9$ & 112 & $2.4 \pm I .1$ & 0.001 \\
\hline Transition time $4.57 \mathrm{~m}(\mathrm{~s})$ & 64 & $9.6 \pm 3.9$ & 213 & $8.8 \pm 4.6$ & 0.023 & 19 & $9.6 \pm 4.8$ & 112 & $6.4 \pm 2.8$ & $<0.001$ \\
\hline Physical activity (kcal) & 88 & $146 \pm 384$ & 213 & $397 \pm 1,086$ & 0.002 & 30 & $59 \pm 200$ & 112 & $951 \pm 2,819$ & $<0.001$ \\
\hline
\end{tabular}

Note: Number of ND group patients was modified according to patient performance ability of particular tests.

Abbreviations: CES-D, Center for Epidemiological Studies Depression; D, diagnostic; ND, nondiagnostic; SD, standard deviation.

the extreme heterogeneity of elderly populations with regard to health and functional status. Among different conceptual approaches, Fried physical phenotype model $^{2}$ remains a reference standard for many studies. ${ }^{11-13}$ However, phenotype diagnostic components require a patient to be sufficiently fit to complete the questionnaires, to perform the handgrip tests, and to walk a $15 \mathrm{ft}$ length twice. These challenges may limit the applicability of the Fried ${ }^{2}$ frailty assessment method in geriatric patients, but a range of these restrictions has not previously been extensively studied. To assess both the usefulness and limitations of frailty components in the elderly population with worsened health, we performed an observational study on geriatric ward inpatients. The patient sample was heterogeneous with typical geriatric morbidities (Table 1). Completion of all five Fried frailty assessment criteria was possible in $65 \%$ of studied patients (D group), which suggests that effective application of the assessment is possible in $60.8 \%-69.2 \%$ (95\% confidence interval [CI]) of individuals in similar inpatient groups. As might be expected, cognitive impairment was an important cause of diagnostic failure in all five Fried frailty assessment criteria (Table 2). Inability to walk was another expected reason. Surprisingly, the lack of previous weight control, which is one of the simplest health measures, appeared also to be an important diagnostic problem in at least $10 \%$ of patients. Paradoxically,

Table 5 Prevalence of prefrailty and frailty among geriatric inpatients ( $n=500)$ according to age, regardless of diagnostic limitations in $35 \%$ patients

\begin{tabular}{llllll}
\hline \multirow{2}{*}{ Age } & Prefrailty & & & Frailty \\
\cline { 2 - 3 } & Patient (\%) & $\mathbf{9 5 \%} \mathbf{~ C l}$ & & Patient (\%) & $\mathbf{9 5 \% ~ C l}$ \\
\hline 60-69 years & 50.0 & $37.3-62.7$ & & 31.7 & $19.9-43.4$ \\
70-79 years & 38.6 & $31.6-45.6$ & & 52.2 & $45.0-59.4$ \\
80-89 years & 31.5 & $25.4-37.6$ & 59.9 & $53.5-66.4$ \\
90 years or above & 23.5 & $9.3-37.8$ & 67.6 & $51.9-83.4$ \\
Total & 35.8 & $31.6-40.0$ & 54.2 & $49.8-58.6$ \\
\hline
\end{tabular}

Abbreviation: $\mathrm{Cl}$, confidence interval. this finding of the study may be the most important message for the elderly population and medical professionals. Health assessment begins with the basics, regularly controlling body weight. The study revealed a very high prevalence of frailty in the studied population, indicating need of urgent introduction of frailty assessment in hospitalized geriatric patients. There is sufficient evidence that management personalization of elderly patients without assessing this syndrome is unfeasible. Despite the limitations experienced in assessing 35\% of our study group, we found that the prevalence of positive Fried frailty assessment in the ND group was not less than in the $\mathrm{D}$ group. A possible method for addressing patients who cannot be assessed by Fried frailty components is to apply a combination of frailty assessment methods. If we consider that a positive Fried frailty assessment needs no further evaluation, then perhaps complementary frailty assessment methods may be useful for cases where Fried frailty assessment is incomplete. Frailty definitions to consider may include the Tilburg Frailty Indicator ${ }^{45}$ or the Clinical Frailty Scale. ${ }^{26}$ The most auspicious proposal to solve some limitations of the Fried frailty phenotype method in relation to geriatric inpatients seems operationalized components proposed by Rockwood et al. ${ }^{10}$ A limitation of this study was the lack of validation of frailty assessment methods for our specific population. Different population characteristics may necessitate the adjustment of frailty assessment values. This issue requires further study.

In summary, we found that Fried frailty criteria are useful in geriatric inpatients, despite diagnostic limitations in a considerable proportion of this specific population. Frailty prevalence exceeded $50 \%$, increasing with age from $31.7 \%$ in sexagenarians to $67.6 \%$ in nonagenarians, which was substantially higher than in other described elderly populations. ${ }^{2,7,12,15}$ Very high prevalence of frailty in this group indicates the need of routine frailty appraisal as a part of a CGA. 


\section{Conclusion}

Fried frailty phenotype criteria seem useful for geriatric inpatient assessment, despite diagnostic limitations. High prevalence of frailty among geriatric inpatients suggests that evaluation for frailty should be considered a part of the CGA.

\section{Acknowledgment}

This project was funded by the Medical University of Silesia grants to statutory work (contracts KNW-1-059/K/3/0 and KNW-1-029/K/4/0) and graduate student research agreement (KNW-2-009/D/4/N).

\section{Disclosure}

The authors report no conflicts of interest in this work.

\section{References}

1. Turner G, Clegg A, British Geriatrics Society; Age UK; Royal College of General Practioners. Best practice guidelines for the management of frailty: a British Geriatrics Society, Age UK and Royal College of General Practitioners report. Age Ageing. 2014;43:744-747.

2. Fried LP, Tangen CM, Walston J, et al; Cardiovascular Health Study Collaborative Research Group. Frailty in older adults: evidence for a phenotype. J Gerontol Med Sci. 2001;56A:M146-M156.

3. Rodríguez-Mañas L, Féart C, Mann G, et al. Searching for an operational definition of frailty: a Delphi method based consensus statement: the frailty operative definition-consensus conference project. $J$ Gerontol A Biol Sci Med Sci. 2013;68:62-67.

4. Morley JE, Vellas B, van Kan GA, et al. Frailty consensus: a call to action. J Am Med Dir Assoc. 2013;14:392-397.

5. Chen X, Mao G, Leng SX. Frailty syndrome: an overview. Clin Interv Aging. 2014;9:433-441.

6. Ruan Q, Yu Z, Chen M, Bao Z, Li J, He W. Cognitive frailty, a novel target for the prevention of elderly dependency. Ageing Res Rev. 2015; 20:1-10

7. Saum KU, Müller H, Stegmaier C, Hauer K, Raum E, Brenner H. Development and evaluation of a modification of the Fried frailty criteria using population-independent cutpoints. J Am Geriatr Soc. 2012;60: 2110-2115.

8. Mitnitski AB, Mogilner AJ, Rockwood K. Accumulation of deficits as a proxy measure of aging. ScientificWorldJournal. 2001;1:323-336.

9. Jones DM, Song X, Rockwood K. Operationalizing a frailty index from a standardized comprehensive geriatric assessment. J Am Geriatr Soc. 2004;52:1929-1933.

10. Rockwood K, Andrew M, Mitnitski A. A comparison of two approaches to measuring frailty in elderly people. J Gerontol A Biol Sci Med Sci. 2007;62:738-743.

11. Op Het Veld LP, van Rossum E, Kempen GI, de Vet HC, Hajema K, Beurskens AJ. Fried phenotype of frailty: cross-sectional comparison of three frailty stages on various health domains. BMC Geriatr. 2015; $15: 77$.

12. Theou O, Cann L, Blodgett J, Wallace LM, Brothers TD, Rockwood K. Modifications to the frailty phenotype criteria: systematic review of the current literature and investigation of 262 frailty phenotypes in the survey of health, ageing, and retirement in Europe. Ageing Res Rev. 2015;21:78-94.

13. Choi J, Ahn A, Kim S, Won CW. Global prevalence of physical frailty by Fried's criteria in community-dwelling elderly with national population-based surveys. J Am Med Dir Assoc. 2015;16(7):548-550. doi:10.1016/j.jamda.2015.02.004.
14. Fried LP, Ferrucci L, Darer J, Williamson JD, Anderson G. Untangling the concepts of disability, frailty, and comorbidity: implications for improved targeting and care. J Gerontol A Biol Sci Med Sci. 2004;59: 255-263.

15. Gale CR, Cooper C, Sayer AA. Prevalence of frailty and disability: findings from the English Longitudinal Study of Ageing. Age Ageing. $2015 ; 44: 162-165$

16. Roland KP, Jones GR, Jakobi JM. Daily electromyography in females with Parkinson's disease: a potential indicator of frailty. Arch Gerontol Geriatr. 2014;58:80-87.

17. Ng TP, Feng L, Nyunt MS, Larbi A, Yap KB. Frailty in older persons: multisystem risk factors and the Frailty Risk Index (FRI). $J$ Am Med Dir Assoc. 2014;15:635-642.

18. Halil M, Cemal Kizilarslanoglu M, Emin Kuyumcu M, Yesil Y, Cruz Jentoft AJ. Cognitive aspects of frailty: mechanisms behind the link between frailty and cognitive impairment. J Nutr Health Aging. 2015; 19:276-283.

19. Lohman M, Dumenci L, Mezuk B. Depression and frailty in late life: evidence for a common vulnerability. J Gerontol B Psychol Sci Soc Sci. 2015:doi:10.1093/geronb/gbu180.

20. Tell GS, Fried LP, Hermanson B, Manolio TA, Newman AB, Borhani NO. Recruitment of adults 65 years and older as participants in the Cardiovascular Health Study. Ann Epidemiol. 1993;3: 358-366.

21. Ellis G, Whitehead MA, Robinson D, O'Neill D, Langhorne P. Comprehensive geriatric assessment for older adults admitted to hospital: meta-analysis of randomised controlled trials. BMJ. 2011;343:d6553. doi:10.1136/bmj.d6553.

22. Deschodt M, Devriendt E, Sabbe M, et al. Characteristics of older adults admitted to the emergency department (ED) and their risk factors for ED readmission based on comprehensive geriatric assessment: a prospective cohort study. BMC Geriatr. 2015;15:54. doi:10.1186/ s12877-015-0055-7.

23. Patel KV, Brennan KL, Brennan ML, Jupiter DC, Shar A, Davis ML. Association of a modified frailty index with mortality after femoral neck fracture in patients aged 60 years and older. Clin Orthop Relat Res. 2014;472:1010-1017.

24. Rockwood K, Song X, MacKnight C, et al. A global clinical measure of fitness and frailty in elderly people. CMAJ. 2005;173:489-495.

25. Kahlon S, Pederson J, Majumdar SR, et al. Association between frailty and 30-day outcomes after discharge from hospital. CMAJ. 2015;187: 799-804.

26. Wallis SJ, Wall J, Biram RW, Romero-Ortuno R. Association of the clinical frailty scale with hospital outcomes. QJM. 2015:doi:10.1093/ qjmed/hcv066.

27. Ritt M, Schwarz C, Kronawitter V, et al. Analysis of Rockwood et Al's Clinical Frailty Scale and Fried et Al's frailty phenotype as predictors of mortality and other clinical outcomes in older patients who were admitted to a geriatric ward. J Nutr Health Aging. 2015;19: 1043-1048.

28. Folstein MF, Folstein SE, McHugh PR. Mini-mental state: a practical method for grading the cognitive state of patients for the clinician. J Psychiatr Res. 1975;12:189-198.

29. Sheikh JI, Yesavage JA. Geriatric Depression Scale (GDS): recent evidence and development of a shorter version. Clin Gerontol. 1986;5: 165-173.

30. Mahoney FI, Barthel DW. Functional evaluation: the Barthel Index. Md State Med J. 1965;14:56-61.

31. Lawton MP, Brody EM. Assessment of older people: self-maintaining and instrumental activities of daily living. Gerontologist. 1969;9: 179-186.

32. Mathias S, Nayak US, Isaacs B. Balance in elderly patients: the "get-up and go" test. Arch Phys Med Rehabil. 1986;67:387-389.

33. Orme JG, Reis J, Herz EJ. Factorial and discriminant validity of the Center for Epidemiological Studies Depression (CES-D) scale. J Clin Psychol. 1986;42:28-33. 
34. Taylor HL, Jacobs DR Jr, Schucker B, Knudsen J, Leon AS, Debacker G. A questionnaire for the assessment of leisure time physical activities. J Chronic Dis. 1978;31:741-755.

35. Siscovick DS, Fried L, Mittelmark M, Rutan G, Bild D, O’Leary DH. Exercise intensity and subclinical cardiovascular disease in the elderly. The Cardiovascular Health Study. Am J Epidemiol. 1997;145: 977-986.

36. Hubbard RE, Andrew MK, Fallah N, Rockwood K. Comparison of the prognostic importance of diagnosed diabetes, co-morbidity and frailty in older people. Diabet Med. 2010;27:603-606.

37. McNallan SM, Chamberlain AM, Gerber Y, et al. Measuring frailty in heart failure: a community perspective. Am Heart J. 2013;166: 768-774.

38. Sanchis J, Bonanad C, Ruiz V, et al. Frailty and other geriatric conditions for risk stratification of older patients with acute coronary syndrome. Am Heart J. 2014;168:784-791.

39. Aaldriks AA, Maartense E, Nortier HJ, et al. Prognostic factors for the feasibility of chemotherapy and the Geriatric Prognostic Index (GPI) as risk profile for mortality before chemotherapy in the elderly. Acta Oncol. Epub 2015 Aug 14.

40. Kelaiditi E, Andrieu S, Cantet C, Vellas B, Cesari M; ICTUS/DSA Group. Frailty index and incident mortality, hospitalization, and institutionalization in Alzheimer's disease: data from the ICTUS Study. J Gerontol A Biol Sci Med Sci. 2015:doi:10.1093/gerona/glv137.
41. Raats JW, van Eijsden WA, Crolla RM, Steyerberg EW, van der Laan L. Risk factors and outcomes for postoperative delirium after major surgery in elderly patients. PLoS One. 2015:doi:10.1371/journal. pone.0136071.

42. Gonthier R, Blanc P, Farce S, Stierlam F. Individualization of the frail elderly people and use of health care services. Psychol Neuropsychiatr Vieil. 2003;1:187-196.

43. Perucca E, Berlowitz D, Birnbaum A, et al. Pharmacological and clinical aspects of antiepileptic drug use in the elderly. Epilepsy Res. 2006;68: S49-S63.

44. Ugolini G, Ghignone F, Zattoni D, Veronese G, Montroni I. Personalized surgical management of colorectal cancer in elderly population. World J Gastroenterol. 2014;20:3762-3777.

45. Gobbens RJ, van Assen MA, Luijkx KG, Schols JM. The predictive validity of the Tilburg Frailty Indicator: disability, health care utilization, and quality of life in a population at risk. Gerontologist. 2012;52(5) 619-631.
Clinical Interventions in Aging

\section{Publish your work in this journal}

Clinical Interventions in Aging is an international, peer-reviewed journal focusing on evidence-based reports on the value or lack thereof of treatments intended to prevent or delay the onset of maladaptive correlates of aging in human beings. This journal is indexed on PubMed Central, MedLine,

\section{Dovepress}

CAS, Scopus and the Elsevier Bibliographic databases. The manuscript management system is completely online and includes a very quick and fair peer-review system, which is all easy to use. Visit http://www.dovepress. com/testimonials.php to read real quotes from published authors. 